Viso - Cadernos de estética aplicada Revista eletrônica de estética

ISSN 1981-4062

$N^{\circ} 17$, jul-dez/2015

http://www.revistaviso.com.br/
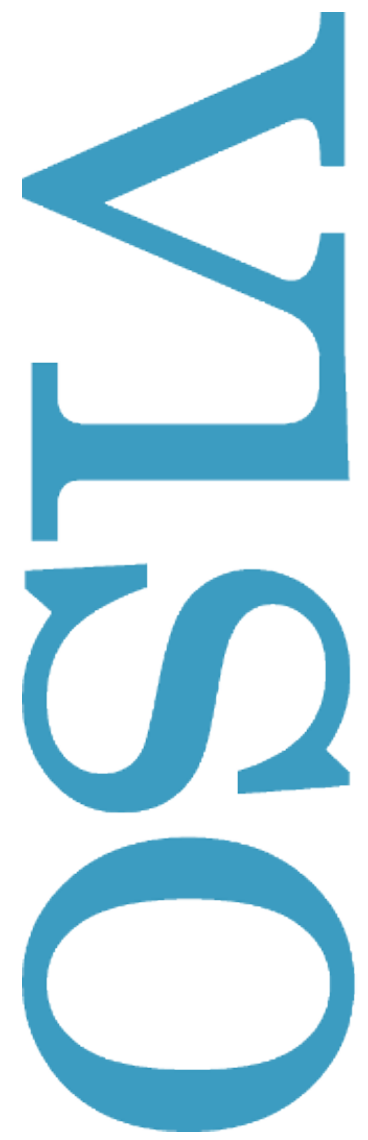

\title{
Odisseu e o sonho do retorno ou O filósofo ardiloso, se isso é possível Izabela Bocayuva
}

Universidade do Estado do Rio de Janeiro (UERJ) 


\section{RESUMO}

Odisseu e o sonho do retorno ou O filósofo ardiloso, se isso é possível

O texto busca acompanhar as andanças de Odisseu até sua volta para a terra natal, descobrindo ao longo do caminho características desse personagem que ajudem a entender a inspiração platônica no mito de $\mathrm{Er}$ de fazer aparecer a personagem do herói itácio escolhendo a vida de um particular desocupado, a vida do filósofo, a vida de Sócrates talvez.

Palavras-chave: Odisseia - Odisseu - mito de Er

\section{ABSTRACT}

Odysseus and the Dream of the Return or The Wily Philosopher, If This Is Possible

The text seeks to follow the wanderings of Odysseus in his return to homeland, discovering along the way characteristics of that character that can help us to understand the Platonic inspiration in the myth of Er to display the itacian hero choosing the life of an unoccupied particular, the life of the philosopher, Socrates' life perhaps.

Keywords: Odyssey - Odysseus - myth of Er 
BOCAYUVA, I. "Odisseu e o sonho do retorno ou O filósofo ardiloso, se isso é possível". In: Viso: Cadernos de estética aplicada, v. IX, n. 17 (jul-dez/2015), pp. 5869.

DOI: 10.22409/1981-4062/v17i/205

Aprovado: 25.01.2016. Publicado: 27.02.2016.

(C) 2016 Izabela Bocayuva. Esse documento é distribuído nos termos da licença Creative Commons Atribuição-NãoComercial 4.0 Internacional (CC-BY-NC), que permite, exceto para fins comerciais, copiar e redistribuir o material em qualquer formato ou meio, bem como remixá-lo, transformá-lo ou criar a partir dele, desde que seja dado o devido crédito e indicada a licença sob a qual ele foi originalmente publicado.

Licença: http://creativecommons.org/licenses/by-nc/4.0/deed.pt_BR

Accepted: 25.01.2016. Published: 27.02.2016.

(C) 2016 Izabela Bocayuva. This document is distributed under the terms of a Creative Commons Attribution-NonCommercial 4.0 International license (CC-BY-NC) which allows, except for commercial purposes, to copy and redistribute the material in any medium or format and to remix, transform, and build upon the material, provided the original work is properly cited and states its license.

License: http://creativecommons.org/licenses/by-nc/4.0/ 
Ambos, querida, conhecemos o limite do sofrimento; tu pranteando o meu retorno multiaflitivo, enquanto Zeus e os outros deuses dorido me arrojavam nos confins, sonhando Ítaca. Ao pluriamor do leito agora que ambos chegamos, cuida do que me pertence aqui. ${ }^{1}$

Menis é a palavra que abre a llíada, Ira - dado o episódio em cena no início dessa obra: a disputa entre Aquiles e Agamemnon. Entretanto, bem mais poderia ser a palavra Eris o verdadeiro princípio da estória/história do ocidente: a divindade Discórdia, não tendo sido convidada para um festim no Olimpo, entra ali escondida e lança sobre a távola um pomo de ouro no qual estava escrito: "tê kallíste", "à mais bela". Hera tenta se apropriar do fruto, mas Afrodite e Atena igualmente o reclamam, pedindo uma solução a Zeus, ele que é delas, respectivamente, marido, irmão e pai. Impossível decidir... Ele resolve, então, passar a tarefa da difícil escolha para o belo pastor Paris, que se decide por Afrodite, depois que esta the promete o regalo que the pareceu o mais interessante: Helena, filha de Zeus, exuberante mortal, bela como uma deusa. Se esta é arrastada à força, como nos quer fazer parecer Górgias no Elogio a Helena, ou se vai conscientemente com o belo mancebo Paris para Troia, não vem ao caso aqui. O que interessa é que, como todos os gregos importantes da época por ela se interessaram, e fizeram juramento de socorrer aquele dos pretendentes de Helena que, já casado com ela, fosse por acaso ultrajado, a partir do acontecimento de seu sequestro, era inevitável partirem agora juntos em guerra. Nesse momento de fazer valer o juramento, Odisseu já estava casado com a bela e exemplar Penélope e tinha um filho recém nascido. Não queria, pois, se juntar aos outros, e, para escapar à promessa, finge até mesmo estar louco: "atrelava a uma mesma charrua animais diferentes, arava a areia infecunda da praia e semeava sal em lugar de grãos de trigo". ${ }^{2}$ Mas Palamedes põe termo a seu ardil, colocando o bebê Telêmaco no caminho em que a charrua, fazendo o sulco na areia, iria passar. Odisseu desvia o arado do bebê, aviando-se, assim, inevitavelmente para a guerra que o afastaria da terra natal por 20 longos anos.

Minha tarefa aqui é acompanhar as andanças multiastutas desse polymetis, desse polytropos, sonhando em voltar para a pátria, até justificar a possibilidade de chamá-lo, ao ardiloso Odisseu, de filósofo. Um primeiro passo nessa empreitada é fundamental, a saber, reconhecer o papel dos deuses junto ao herói. Mas em primeiro lugar se deveria dizer, isso sim, o papel deles junto aos heróis, no plural. Assistimos, ao longo de toda a llíada, não só à presença dos deuses. Na verdade, cada acontecimento tem neles seu impulso primeiro. Cada ânimo e cada arrefecimento de um herói tem sua origem num deus que o estimula ou que o abandona. Se entre os homens que foram para a guerra de Troia apenas vemos os heróis serem acompanhados de algum ou alguns deuses, entre os heróis há os mais e os menos queridos. É até mesmo raro que um deus chegue a falar diretamente com um herói, como é o caso da bela cena de Atena aparecendo para Aquiles bem no princípio da llíada. Na tradução de Haroldo de Campos: 
Então, do céu, Atena desce. Enviou-a Hera,

dos braços brancos, que ama os dois [Aquiles e Agamemnon], por ambos vela.

Por trás segura-lhe os cabelos louros, só

visível para ele; ninguém mais vê.

Espanta-se o Peleide; gira o corpo, e logo

dá com Palas Atena: olhos terríveis brilham! ${ }^{3}$

$\mathrm{E}$, a partir desse encontro, os dois conversam amplamente. Um outro exemplo de forte intervenção divina é Afrodite salvando seu protegido Paris da luta com Menelau que fica como bobo procurando, em meio a uma névoa, o seu opositor. Há inúmeros outros casos que não vamos aqui enumerar. O que nos interessa agora pontuar é o quanto, dentre todos os heróis, um em especial teve a proteção dos deuses, mais especificamente de Atena, o herói Odisseu, bisneto de Hermes, por parte de mãe. Não houve quem mais escutasse a voz divina. Nada mais adequado para um bisneto de Hermes. Uma ascendência também significativa em sua habilidade multiastuta.

A Odisseia inicia com Atena e Zeus confabulando o retorno do herói, ora preso na ilha da deusa Calipso, chorando copiosamente dia após dia enquanto sonhava com sua volta à longínqua terra natal. Ele não queria se tornar um imortal, como havia the proposto a belíssima deusa. Seu desejo desde que deixou, a contragosto, Ítaca, sempre fora o de para lá retornar. Odisseu queria logo repatriar-se.

Mas a confabulação dos dois deuses protetores de Odisseu no início da Odisseia pode fazer parecer que só de sorte divina vivia esse herói. Não é o caso. Os dez anos de pena e sofrimento desde o fim da guerra de Tróia, enquanto lutava agora para voltar para casa, são fruto da intervenção do poderoso Poseidon. É que nem sempre a astúcia do herói se aliou a seu desejo pátrio. Sua philomatia, amor à honra, o impedia. Foi-lhe impossível conter a hybris de querer se mostrar como grande ardiloso. Tendo se apresentado com o nome "Ninguém" ao ciclope Polifemo, o qual ele acabou cegando com ajuda de seus companheiros, conseguiu escapar da ilha do gigante, filho de Poseidon. Se tivesse, ao partir, mantido, como sendo o seu, esse nome super esperto, como saberiam que foi ele o astuto cegador? Mas, ao zarpar, fez questão de revelar sua identidade, conquistando, com isso, a fúria do poderoso deus dos mares, que vai persegui-lo até mesmo quando já estiver em cena o apoio de Atena e Zeus.

Em relação a nosso primeiro passo, portanto, extraímos do já lembrado até aqui que Odisseu é um herói permanentemente em contato com os deuses de modo sempre intenso, seja a favor, seja contra. Sua escuta atenta é realmente singular. Ele não a obstrui nem mesmo quando é o caso do perigosíssimo canto das sereias. Para ouvir essas divindades mortíferas ele se faz amarrar no mastro de sua nau de modo tão cerrado quanto Parmênides encerra em si mesmo o to eón, o Ser inviolável, inamovível. Para essa semelhança nos alerta Barbara Cassin em seu livro de tradução e comentário do poema de Parmênides. Ela diz: 
O palimpsesto superpõe, com efeito, a imobilidade de Ulisses ligado ao mastro por seus companheiros no episódio das Sirenes, e a imobilidade disso que será a esfera, retida por uma necessidade poderosa dentro dos liames do limite: um como o outro "permanecem aqui mesmo solidamente plantados no solo" (Od., XII, 161). ${ }^{4}$

Cassin, falando em palimpsesto, brinca com a possibilidade de Parmênides ter raspado e escrito em cima do papiro da Odisseia. O Ser teria sido o herói de Parmênides, assim como Odisseu fora o herói da Odisseia de Homero. Mas, com essa articulação entre Parmênides e Odisseu, somente pode parecer que aludimos à possibilidade de justificar a minha proposta de ver em Odisseu um filósofo. Na verdade, ainda não tocamos no ponto preciso. Antes de nos encaminharmos a ele, nas andanças desse herói trágico, cabe considerar um empreendimento seu extremamente valioso na direção do que nos interessa. Tirando Orfeu, Odisseu foi o único mortal que penetrou, em vida, o mundo dos mortos. Mas a ida deles ao Hades tem características bem diferentes. Orfeu, com a intenção de buscar sua amada que havia morrido, consegue ter acesso às divindades ínferas e se atém a esse encontro. Já o herói grego, não sem a orientação de uma feiticeira, Circe, por sua vez encantada por ele, vive, vivo, a vida, ou será melhor dizer?, a morte, dos mortos. Fala normalmente com o fantasma de sua mãe, de Aquiles e de outros companheiros, depois de ter tido o privilégio único de obter preciosas informações do vidente Tirésias, que, mesmo depois de morto, era o único a não perder a lucidez relativamente aos caminhos ainda iluminados pelo sol, pela lua e as estrelas. Como já dissemos, a ida de Orfeu ao Hades implica um pontual encontro com as divindades daquele lugar. Algo extremamente valioso, sem dúvida, mas que não inclui a convivência, ainda que entre os fantasmas dos homens. Já a ida de Odisseu parece mais ser um evento. Claro que não podemos dizer que se trata de uma festa, porque não é realmente esse o caso, mas ele, dando de beber sangue aos fantasmas, faz com que, por ora, eles tenham força de expressão, chegando até mesmo a expressar vontades, como é o caso de Aquiles, que, se pronunciando - pela tradução de Trajano Vieira -, chega a dizer ao herói itácio: "preferiria lavrar a terra de um ninguém depauperado, que quase nada tem do que comer, a ser o rei de todos os defuntos cadavéricos". ${ }^{5}$

Poder ir, vivo, ao Hades, absolutamente não é algo de pouca monta. Simbolicamente isso significa sabedoria plena, significa ser um mortal que tem acesso à totalidade. Talvez por isso alguns - ainda que poucos - intérpretes do proêmio do poema de Parmênides entendam que ali está acontecendo uma katabasis, já que o poeta passa a ter acesso a toda a verdade, quando se encontra com a Deusa inominada. No diálogo Menon, Sócrates, ao falar em anamnese, alude a essa condição de plena sabedoria: conhecer o que se passa no mundo sublunar e o que se passa no Hades.

Mas há mais uma característica do herói itácio que o aproxima da filosofia. O traço mais decisivo: o desejo de voltar às raízes. Odisseu sonhava desesperadamente conseguir voltar para os braços de Penélope. E ele por fim consegue que isso se torne realidade, não sem muito esforço, como o sabemos. Mas para conseguir se vingar da ousadia dos pretendentes que devastavam sua propriedade, ajudado por Atena, ele se traveste de 
mendigo até que, em momento oportuno, com força e estratégia suficientes, consegue matá-los todos. Quando, porém, quer ser reconhecido por sua própria mulher, esta não se deixa facilmente convencer e, por precaução, usa de um estratagema. Penélope, como seu dileto marido, também era astuta. Ela orienta a criada Eurínome, propositalmente na frente do herói, a preparar a cama do suposto marido fora do quarto do casal. Era uma provocação, já que seria impossível mover aquela cama, mas isso era um segredo que apenas Odisseu poderia conhecer, já que ele mesmo tinha sido o autor do leito construído na base do tronco de uma imensa oliveira que conservava suas raízes fincadas no solo pátrio. Criticando a esposa ele diz, na tradução de Vieira:

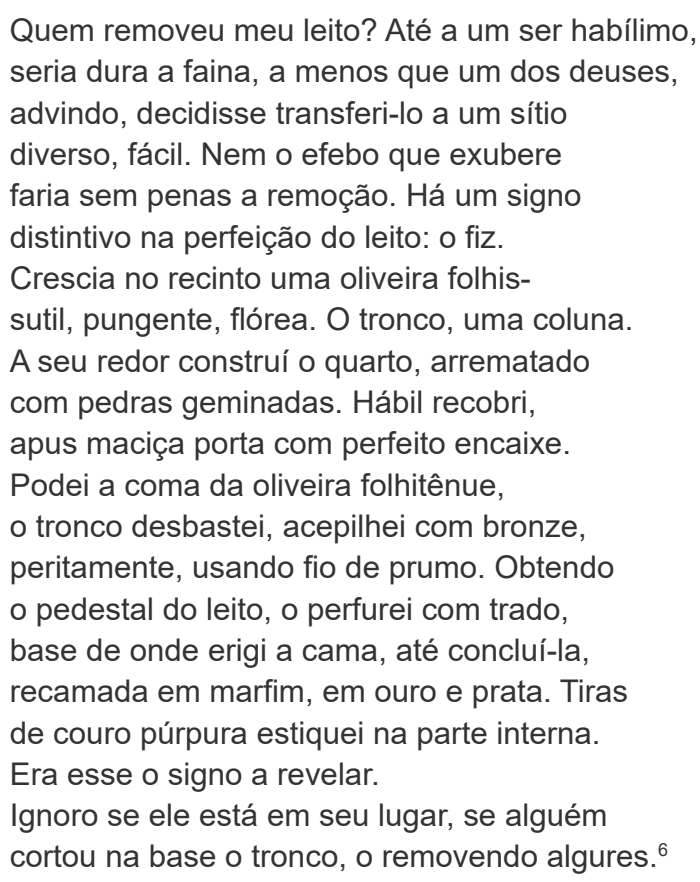

Com essa revelação, Penélope já não pode mais duvidar de que está diante do marido por tanto tempo esperado. Mas o que nos importa aqui é o que está subentendido nesse segredo. A casa de nosso herói, em outros termos, sua pátria, está muito bem enraizada, muito bem fundada. Em torno de sua cama de raízes fincadas construiu sua casa, seu mundo, sua pátria. Quer dizer que, durante toda a sua jornada, Odisseu, como um filósofo, foi em busca do fundamento, foi em busca do enraizamento, do começo, do princípio do mundo, seu próprio mundo.

Isso não passou desapercebido por Platão. Todo grego conhecia de cor as andanças de Odisseu, mas não houve quem mais bem se aproveitasse delas do que o filósofo da República, a ponto de encontrar lugar, nesta mesma obra, para esse grande herói. Na verdade, de uma maneira geral, o uso que esse filósofo faz do mito ao longo de toda a sua obra mostra muitíssimo como ele era tributário e admirador do poeta Homero, ainda que tenha tido necessidade de enfrentar, de contrariar, a influência deste na formação do homem grego. Não vou discutir essa questão aqui. Antes, interessa-me, isso sim, 
explorar o quanto o mito do final da República, o mito de Er, não teria existido sem Homero e, além disso, vou interpretar a interpretação feita ali, por Platão, da personagem trágica Odisseu. Veremos, com isso, finalmente, por que ouso chamar o astuto, e tantas vezes mentiroso, herói de filósofo. Entendo que quem faz isso pela primeira vez é o próprio Platão.

Como se não bastasse mostrar o interior do Hades através da visita que nosso herói fez àquele lugar no canto XI da Odisseia, Homero nos faz ir até lá novamente no epílogo da obra, o canto XXIV. Desta vez não é através dos olhos e ouvidos de Odisseu que temos a oportunidade de ver e ouvir a fala dos mortos. Agora, quem havia descido ao Hades, guiados naturalmente pelo deus Hermes, o condutor oficial das almas, eram todos os vários pretendentes de Penélope recém chacinados pelo herói itácio e seu filho Telêmaco, não sem grande ajuda de Atena. O que é digno de atenção nesse momento da poesia homérica é a franca conversa dos mortos entre si. Os que chegam dão notícias do mundo sublunar: falam de graças como é o caso da notícia a respeito da vibrante fama de Aquiles e contam também suas desgraças. Os mortos já há mais tempo também dão informações que talvez os outros que chegam desconhecessem. Agamemnon, por exemplo, depois de ter ouvido a alma de Anfimedonte, um dos pretendentes, narrando seus tamanhos revezes, lamenta sua própria má sorte de ter se casado com uma mulher traidora e assassina, Clitemnestra, comparando-se com Odisseu, este sim bem aventurado de ter tido a fidelíssima Penélope como esposa.

No mito de Er, no final da República, tem lugar igualmente uma conversa amigável entre os mortos. É certo que há elementos no mito que Platão conta que não são de influência homérica. Naquele mito, as almas recém chegadas ao Hades são julgadas e, em função desse julgamento moral, são distribuídas para o alto ou para baixo para viverem, respectivamente, delícias ou castigos. Em Homero não há julgamento de nenhum tipo para os mortos, porque, acreditava-se, já era castigo suficiente estar morto. Para vermos o quanto essa perspectiva era contundente no grego daquela época, é só lembrarmos a fala de Aquiles que citamos logo acima.

Guardadas as diferenças, Platão está numa tradição que recorre ao mito para atingir o imponderável. Em Platão, pode-se tranquilamente afirmar que o mito, por ele aproveitado ou mesmo inventado, tem inúmeras vezes caráter especulativo. É o caso do mito em questão neste momento cujo conteúdo aponta para um comportamento ético ideal, conduzindo à boa vida, eû práttein. Através do mito do fim da República, nós ficamos sabendo o que ocorre no Hades pelo testemunho do corajoso guerreiro Er, que acorda depois de uma espécie de catalepsia e nos conta o que viu quando estava passageiramente morto. Viu primeiramente o julgamento de almas que acabavam de morrer. Posteriormente assiste ao retorno de outras ao prado comum, tanto descendo da viagem de 1000 anos no alto, quanto voltando da torturante viagem no Tártaro. Nesse momento, as que se conheciam conversam, amigavelmente, contando ou suas agruras ou sua sorte, tal como vimos acontecer na Odisseia. 
O que mais nos interessa nesse mito, começa, pois, a acontecer a partir de agora. Há todo um belo cenário no Hades de luzes intensas e coloridas componentes da estrutura da roca da deusa Necessidade, com direito ao canto das Sereias. As Moiras, filhas da Necessidade, também compunham a cena. Sentadas em círculo, cada uma em seu trono, cantavam ao som da melodia das Sereias, Láquesis, o passado, Cloto, o presente e Átropos, o futuro.

Cloto, tocando com a mão direita o fuso, ajudava a fazer girar o círculo exterior, de tempos em tempos; Átropos, com a mão esquerda, procedia do mesmo modo com os círculos interiores; e Láquesis tocava sucessivamente nuns e noutros com cada uma das mãos. ${ }^{7}$

As almas, assim que nesse lugar chegavam, tinham de ir todas para junto de Láquesis, no colo de quem estavam lotes e modelos de vida que um profeta, depois de os ter recolhido, com eles nas mãos passa a mensagear do alto de uma plataforma, falando assim:

Declaração da virgem Láquesis, filha da Necessidade. Almas efêmeras, vai começar outro período portador da morte para a raça humana. Não é um daimon que vos escolherá, mas vós que escolhereis o daimon. O primeiro a quem a sorte couber, seja o primeiro a escolher uma vida a que ficará ligado pela necessidade. A virtude não tem senhor; cada um a terá em maior ou em menor grau, conforme a honrar ou desonrar. A responsabilidade é de quem escolhe. $O$ deus é isento de culpa. ${ }^{8}$

Dizendo isso, atira os lotes a esmo, o que torna evidente a ordem da escolha. Depois coloca aos pés de todos um número de modelos de vida bem maior do que o número de almas presentes e diz:

Mesmo para quem vier em último lugar, se escolher com inteligência e viver honestamente, espera-o uma vida apetecível, e não uma desgraçada. Nem o primeiro escolha sem cuidado [ameleito], nem o último sem coragem [athumeito]. ${ }^{9}$

É extremamente importante essa fala do profeta mensageiro de Láquesis no mito de $\mathrm{Er}$ para o que estou querendo alinhavar desde algum tempo. Trata-se do "recado" de uma deusa. As almas estão à escuta. $O$ mensageiro fala de um daimon a ser escolhido. Do que poderia se tratar isso, que pode ser de um modo ou de outro, e diz respeito a uma divindade? Entendo que o daimon ao qual cada um vai se ligar é aquilo que vai realmente caracterizar cada um como alguém que de fato dá ouvidos ou não à fala do deus - no caso, a mensagem que alerta para o cuidado e inteligência na escolha - e que, dando ouvidos a ela tende à virtude, e, desse modo, a uma vida eu-daimônica, isto é, a uma vida capaz de escuta. Escutar a divindade implica, pois, em já estar se fazendo acompanhar bem da divindade, o que proporciona a este que assim o faz uma boa vida. A continuação da mensagem do profeta também é muito importante no sentido de reforçar que todos estão aptos a uma tal boa vida, a uma tal eudaimonia. 
Platão passará a exemplificar, então, modos de escolha de modelos de vida usando, na maioria das vezes, já conhecidas personagens míticas para que se possa experimentar com clareza o que ele quer sugerir em termos de uso cuidadoso e possível da inteligência. O primeiro exemplo nos interessa muitíssimo, mesmo não sendo o caso de uma personagem mítica já conhecida. Ele é realmente o paradigma de uma má escolha. Trata-se da alma a quem coube escolher em primeiro lugar. Aparentemente um homem de sorte... Mas muito pouco cuidadoso ou inteligente. Escolhera, por "insensatez e cobiça", a vida de um tirano que iria chegar, por exemplo, a comer os próprios filhos e que passaria ainda por muitas outras desgraças. Platão faz questão de detalhar a causa de ele ter feito uma escolha tão infeliz. Ele teria vivido numa cidade bem governada em sua existência anterior e por isso, meramente por hábito, viveu virtuosamente, de tal forma que quando, morto, foi julgado, mereceu subir e viver 1000 anos de delícias ${ }^{10}$ antes de descer ao prado e fazer a peregrinação até o ponto em que ouviu o mensageiro de Láquesis; mas agora, por sua negligência, estava fadado a, futuramente, ter que baixar ao Tártaro. Platão é categórico quando fala dele: fora virtuoso por hábito e não por filosofia. Ele era aneu philosophias, sem filosofia. Não ouvira nada que o mensageiro anunciou, e isso de tal forma que responsabilizou justamente os deuses por sua desgraçada escolha. Se coloca, pois, a ranger dentes, atitude que não mais vai abandoná-lo. Guardemos todos os detalhes dessa primeira escolha. Trata-se do contraponto necessário e importantíssimo para a colocação de nossa hipótese, a saber, de que Odisseu pode ser visto como filósofo nesse mito platônico.

E continuamos, ao longo do mito, a assistir a inúmeras escolhas de modos de vida futuros atrelados ao modo de vida anterior, sempre no sentido de procurar o bem viver. A má escolha do primeiro a escolher não deixa de ter sido algo feito nessa mesma direção. Apenas, ele que era inconsequente e pouco sagaz confundia, por cobiça, o "melhor" modo de vida, com o modo de vida de um tirano.

Finalmente chegamos à alma de Odisseu. Platão, propositalmente, para ficar bem gritante o contraste com aquele que foi o primeiro a escolher, fez à alma de Odisseu cair a sorte de ser simplesmente, nada mais, nada menos, que a última a escolher a vida a levar futuramente. Quando é sua vez, avança, mas se lembrando sempre dos sofrimentos nas andanças anteriores, abdica do amor às honras [philotimia] ${ }^{11}$, exatamente aquele ímpeto que o levou à hybris responsável pela revelação de seu verdadeiro nome ao ciclope Polifemo, despertando a ira de Poseidon. Por muito tempo procurou a vida de um andros idiotou apragmatos. ${ }^{12}$

Descobriu-a a custo, jazente em qualquer canto, e desprezada pelos outros; ao vê-la declarou que faria o mesmo se lhe tivesse cabido o primeiro lugar, e pegou-a contente [asmenen]. ${ }^{13}$

O que seria a vida de um aner idiotes apragmon? A tradução de Maria Helena da Rocha Pereira é "a vida de um particular tranquilo". É imprescindível agora explorar um pouco 
esta tradução. Aner é termo que caracteriza o varão, o homem, por oposição à mulher. ${ }^{14}$ Para um grego, nascer homem é mais do que nascer mulher, por isso, é algo desejável por si mesmo. Idiotes é um substantivo que significa: simples particular, homem privado, por oposição a rei, homem público, de Estado, e ainda, todo homem de condição modesta, simples cidadão. ${ }^{15}$ Heráclito, por ter escolhido estar ao lado das crianças no templo de Ártemis, tendo abdicado do importante cargo político que lhe era de direito, em nome do irmão, era, portanto, um idiotes. Outro idiotes contumaz: Sócrates; e outro: o próprio Platão. Apragmon é adjetivo que quer dizer: desocupado, que gosta da tranquilidade, que permanece estranho às tarefas públicas. ${ }^{16}$ Segundo Platão, Odisseu, cuidadosamente e com a inteligência que lhe é característica, escolhe a vida de um homem comum e desocupado. Chegamos ao ponto que eu queria... Não se poderia considerar uma vida assim descrita exatamente como sendo uma vida de ócio? Mas a vida de ócio não é precisamente o modus vivendi de todo filósofo, não é precisamente o modus vivendi de Sócrates? Então, Odisseu teria, tendo ouvido muito bem a mensagem de Láquesis, com bastante cuidado, escolhido exatamente uma vida de filósofo, a qual, pelo que ele diz, seria a melhor escolha inteligente em qualquer circunstância, pois teria sido a sua escolha mesmo que the tivesse cabido escolher em primeiro lugar, ou em segundo, ou em terceiro, etc. Outro ponto importante que é especialmente pontuado por Platão é a alegria dessa escolha. Ao contrário daquele primeiro que imprudentemente escolhera a vida de tirano e se irritara, por isso, com os deuses, Odisseu se alegra com sua escolha, mostrando precisamente sua eudaimonia por esse futuro eu prattein, por esse futuro bem viver.

Platão teria feito, portanto, através do mito, o herói trágico Odisseu, de um philotimos, por sagacidade e experiência, se transformar em um philosophos. Mas é que ele já era um filósofo, por contraste com aquela alma imprudente que vivera, anteriormente, sem filosofia, uma vida virtuosa. Estamos diante de um círculo vicioso. Para ter escolhido a vida de filósofo, Odisseu teria sido virtuoso, com filosofia, anteriormente. Na verdade, não pode ter pouco peso a força de quem enfrentou tantos perigos e teve que suportar tantas perdas sempre com o mesmo comedimento. Assim, apesar de precisar tantas vezes ardilosamente mentir ao longo de suas andanças de enfrentamento, o que, tomado moralmente de modo dogmático seria considerado vicioso, a grandeza de Odisseu impõe o reconhecimento de que há mentiras úteis. Assim, a figura desse grande herói inaugura a possibilidade de se pensar um filósofo que é ardiloso, se isso se faz necessário. $\mathrm{E}$ o autor do Hipias Menor ${ }^{17}$ não teria aprendido isso com o mais astuto herói de Homero ao afirmar, ele próprio, na República, que a mentira é de certa forma necessária, quando se tem como fim encaminhar tudo da melhor maneira possível?

Fica lançada a provocação.

Sem dúvida pode-se pôr em questão a identificação que faço do aner idiotes apragmon com a figura do filósofo, pois, afinal, no livro $\mathrm{V}$ da própria República é proposto que o filósofo seja o rei, o homem público por excelência da Kallipolis. Eu defendo meu 
argumento considerando que o filósofo de quem fala Sócrates na República só deve ser o rei porque é, a princípio, um idiotes apragmon, porque é, foi e sempre será diferente do homem público. É só lembrarmos o quanto Platão faz questão de frisar o quanto é próprio do verdadeiro filósofo não ser nada parecido a alguém que se candidataria ao cargo de rei, ou algo que o valha. Nesse sentido, quando se propõe ali que o filósofo seja o rei, há que se ter em vista o quanto está em jogo um inteiramente outro modo de ver a política. Pois, em se tratando da política vigente, cabe realmente um filósofo se manter afastado dela como é o caso da emblemática personagem filosofante, Sócrates, e de tantos outros. Platão mesmo nos faz lembrar, no Teeteto, de Tales caindo num buraco por permanecer olhando o céu, estando totalmente alheio do mundo imediato, mundo esse que deve ser exatamente aquele que prende a atenção e exige os cuidados de um político comum.

* Izabela Bocayuva é professora do Departamento de Filosofia da UERJ.

${ }^{1}$ HOMERO. Odisseia. Tradução de Trajano Vieira. Campinas: Editora 34, 2011, XXIII, v. 350-355.

${ }^{2}$ MEUNIER. Nova mitologia clássica. A legenda dourada. Tradução de Alcântara Silveira. São Paulo: IBRASA, 1976, p. 273.

${ }^{3}$ HOMERO. Odisseia. Tradução de Haroldo de Campos. São Paulo: Arx, 2002.

${ }^{4}$ CASSIN, B. Sur la nature ou sur l'étant. La langue de l'être? Paris: Éditons Du Seuil, 1998, p. 55 (tradução nossa do texto francês).

${ }^{5}$ HOMERO. Odisseia. Tradução de Trajano Vieira. Campinas: Editora 34, 2011.

${ }^{6}$ Ibidem, XXIII, v. 184-204.

${ }^{7}$ PLATÃO. A república. Tradução de Maria Helena da Rocha Pereira. Lisboa: Calouste Gulbenkian, 1983, 617c5-d1.

8 Ibidem, 617d6-e5.

${ }^{9}$ Ibidem, 619b3-6.

${ }^{10}$ Prêmio pela virtude.

${ }^{11}$ Ibidem, 620c5.

${ }^{12}$ Ibidem, 620c6-7.

${ }^{13}$ Ibidem, 620c7-d2.

${ }^{14}$ BAILLY. Dictionnaire Grec Français. Paris: Hachette, 1950, p. 159.

15 Ibidem, p. 958.

${ }^{16}$ Ibidem, p. 253.

17 Nesse diálogo o sofista Hipias fica perplexo e contrariado diante de um Sócrates que, argumentando rigorosamente, afirma ser Odisseu melhor que Aquiles porque este mente involuntariamente enquanto aquele, o itácio, mente voluntariamente. É como se houvesse um mentir que tivesse seu porquê, e por isso mesmo fosse o melhor, tal como o disfarce de mendigo de Odisseu em seu retorno envolto em trama, medindo forças. Haveria, pois, um certo tipo de mentir onde o falso é justamente o verdadeiro. 